In this case the temperature never exceeded $100 \cdot 2^{\circ} \mathrm{F}$. and there was an absence of the usual symptoms of general peritonitis. Mr. Targett reported of the specimen that it consisted of the right uterine appendages and a gestation sac the latter being inclosed within the outer end of a dilated Tallopian tube :-

On section the wall of the gestation sac was found to be infiltrated with blood-clot and fibrin, as in a tubal mole. Where suppuration has occurred the placental tissue is separated from the inflamed tube by pus, and chorionic villi are in actual contact with the inflammatory products. The mucous membrane of the tube is destroyed and replaced by granulation tissue. The tumour is roughls spherical in shape and measures $8 \times 7 \times 6$ centimetres $\left(3 \frac{1}{4} \times 2 \frac{3}{4} \times 2 \frac{1}{4}\right.$ inches) in its chief diameters after fixation in formalin. A portion of the posterior wall of the mass has been removed and reveals two cavities. The larger of these is the gestation sac containing a foetus, while the smaller is a space formed between the gestation sac and the wall of the dilated Fallopian tube. In the recent state this latter space was filled with very offensive pus. Flattened out on the half of the tumour nearest to the uterus is the right ovary. The characters of the gestation sac are precisely those of an apoplectic or blighted ovum. It measures about five centimetres in its chief diameter, and its wall is composed largely of blood-clot in various stages of consolidation. The interior is lined with amnion which is unevenly raised by hæmorrhages beneath it A fotus measuring 2.75 centimetres is attached to the wall of the of the sac by an oedematous umbilical cord 175 centimetres in length, corresponding with the stage of development at the end of the second month. The suppurating cavity, semilunar in shape, represents that part of the dilated ampula of the tube not occupied by the gestation ended in a molar pregnancy or apoplectic ovum, and that secondary

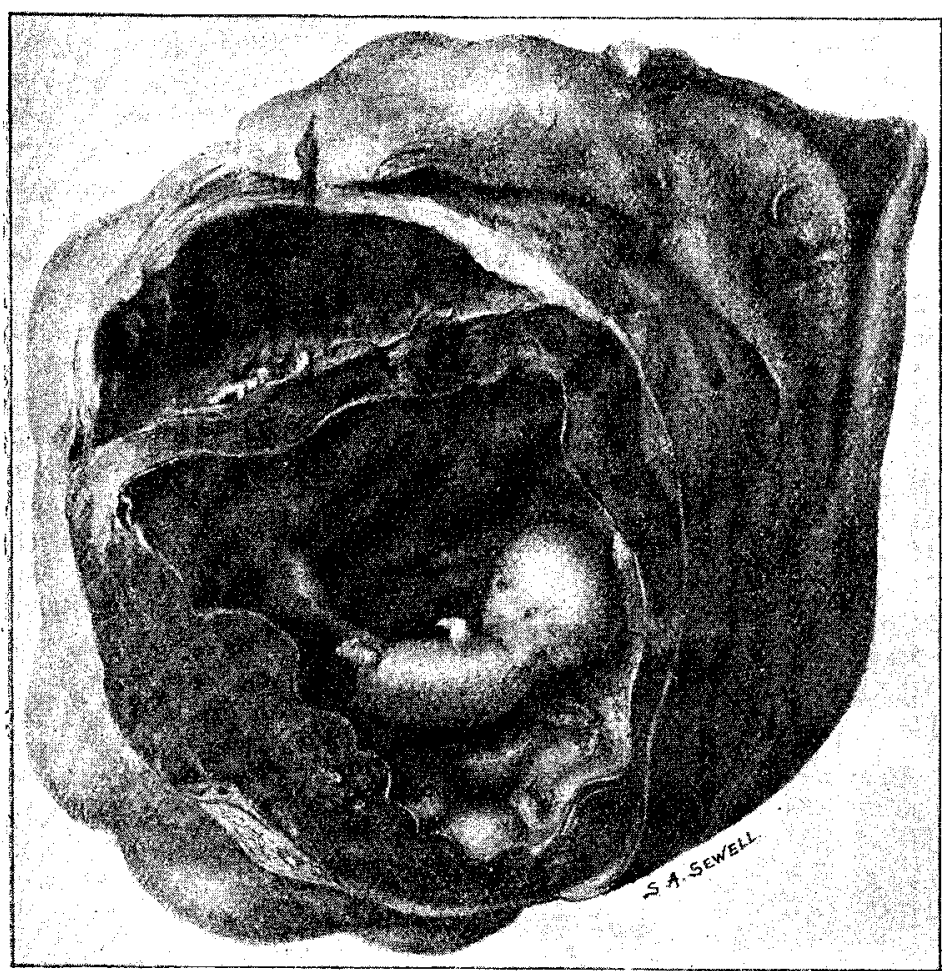

Gestation sac with fœetus; the upper cavity shown in the drawing is that in which the septic fluid was contained.

euppuration had been set up within the dilated tube and around the ovum. Consequently the pus had collected in that internal cavity at only one spot upon the wall of the dilated tube.

It would seem that the source of infection must have been through the adherent bowel. The patient having suffered from retroversion of the uterus the early symptoms might naturally lead to the impression that it was an enlarged retroverted and gravid uterus and tend to make the diagnosis less certain. From the size of the tumour and the impression which it conveyed of fixation by adhesions I determined on the abdominal operation, though, as events proved, considering the nature of the sac, the vaginal one would have been the safest one for the patient. Had I a similar case again, with rupture of a fotid sac, having protected the bowel I should first char the margins of the abdominal wound with the thermo-cautery, and then at some distance from the charred surfaces make a new incision at either side before closing the wound. Not long since I opened the abdomen for a large and very fotid subperitoneal abscess which had penetrated the peritoneum. Having evacuated the pus and thoroughly cleansed out the abdominal cavity with formalin, disinfecting the edges of the wound, which were covered by a foul and deep slough, I removed this at either side before bringing the edges together and drained. Contrary to my expectation the patient made an excellent recovery.

Harley-street, $W$

\section{ARE NOT SOME PATIENTS SAID TO BE AFFLICTED WITH GASTRIC ULCER \\ REALLY SUFFERING FROM A DIFFERENT DISEASE?}

BY W. HALE WHITE, M.D., F.R.C.P. LOND., PEYSICIAN TO, AND LEOTURER ON MEDICINE AT, GUY'B HOBPITAL.

IT is allowed that the malady commonly diagnosed as gastric ulcer is very much more common in women than in men; also that many more cases in women occur in the two decades from 20 to 40 than in any other two decades, whilst in men the disease is commoner later in life. Further, the mortality in men is higher than in women. For instance, Dr. R. Saundby has stated ${ }^{1}$ that among 15 deaths at the Birmingham General Hospital due to gastric ulcer 11 occurred in men and four in women, a striking contrast when we remem. ber the greater frequency of the diagnosis of gastric ulcer in women. Because of these facts I have for years been accustomed to teach that one of two conclusions must follow : either the outlook of gastric alcer in women is much more favourable than it is in men, or many cases occurring in women and classified as gastric ulcer at the bedside are really instances of some other undescribed malady. I have also maintained that the second is the more likely view, for it relieves us of the difficulty of explaining the otherwise obscure facts that so-called gastric ulcer is at its maximum frequency earlier in women than in men and is commoner in women than in men, although actually more fatal in men, and this view renders it more easy to understand why the condition diagnosed as gastric ulcer is so frequently associated with chlorosis, for this disease is almost confined to women and is met with at about the same time of life as that at which the diagnosis of gastrio ulcer is most frequently made. I have therefore often suggested that there is a disease met with chiefly, or perhaps only, in women usually between 20 and 40 years old; that its chief symptoms are gastric pain, nausea, sickness, and hæmatemesis, that these symptoms are not dependent upon ulceration of the stomach, any ulceration that may be present being quite superficial and no more than might occur secondarily to the hæmorrhage; and that the diagnosis from genuine gastric ulcer occurring in women is very difficult, yet the facts that in spite of serious gastric symptoms extending over years the patient is not wasted, has been or is often chlorotic, and has none of the mechanical effects of gastric ulcer, such as adhesions, pyloric stenosis, or subphrenic abscess, may help us to a right conclusion.

The prognosis is entirely different from that of gastrio ulcer, for, apart from hæmorrhage, these patients are not liable to the numerous serious complications of gastric ulcer. The prognosis is good, although relapses are frequent. Occasionally, but excessively rarely, the sufferers may die from hæmorrhage, and then no cause for it is found. The disease is in many cases, I apprehend, closely related to chlorosis, for it certainly is often associated with it or occurs in those who have formerly suffered from chlorosis, but it may, I think, exist apart from chlorosis. Until we know something of the cause of chlorosis we can hardly hope to know what the association is. I have not hitherto liked to put this view on paper for want of direct evidence in its favour, but now that surgeons have taken to opening the stomach for severe bleeding some support is fortheoming. Operators are already accustomed not to find an ulcer even when the hæmorrhage has been severe. Thus Mayo Robson * says: "If no ulcer be found anywhere and the bleeding proves to be capillary or from small undiscoverable ulcers." I take it that here we may assume that if the ulcer proves to be undiscoverable no ulcer exists. My proposition seems also to be supported by the following quotation from Mayo Robson" " "Erosions.-Of these Dieulafoy has described two varieties: (a) simple erosions, consisting apparently of mere abrasions of the surface

1 Brit. Med. Jour., vol. 11., 1900, p. 1613.

3 Brit. Med. Jour., Feb. 2nd, 1901, p. 257 
epithelium, which, though so small as to be scarcely perceptible to the naked eye, may give rise to the most alarming hæmorrhage. On the post mortem table abrasions of this kind may be easily overlooked, but as seen when hæmorrhage is going on the mucous membrane seems to be studded with numerous bleeding points." This surely is a different disease from that which we know to be gastric ulcer, with its possible sequelæ of adhesions, sub diaphragmatic abscese, and other well-known complications, and it is surely more likely that the abrasions were the result, rather than the cause, of the hæmorrhage.

Byrom Bramwell ${ }^{4}$ does not go so far as the proposition I am urging, but he does go as far as to say, "I am disposed to think that gastric ulcer in the young (chlorotic) female is on the whole a less serious and fatal disease than in men," and he proceeds to suggest that the reason is that in young chlorotic women the ulceration is superficial. I would go further and say that probably many of these cases in women are examples of a different disease, and I would suggest that as the ulceration even if present is superficial and trifling it may be secondary to the hæmorrhage. In other words, that the essence of the disease is not ulceration but a liability to gastric hæmorrhage independent of ulceration.

Dr. Newton Pitt kindly allows me to refer to a patient under his care, as she illustrates my point. She was a woman, aged 37 years, who for seven years had been liable to attacks of gastric pain, vomiting, and hæmatemesis. She was admitted into Guy's Hospital blanched and collapsed and died from hæmatemesis. The most careful examination at the necropsy failed to detect any source for the blood. The stomach was sent to the museum and the curator, Dr. Lauriston Shaw, failed to find any lesion of it.

Dr. Frederick Taylor also kindly allows me to mention the case of a woman who was admitted into Gay's Hospital under his care. She had for several years been seen by Dr. Lauriston Shaw as an out-patient for gastric pain, vomiting, and hæmatemesis The stomach was opened hut no ulcer or source for the hæmorrhage could be found. The patient made an excellent recovery.

Cases can also be quoted from literature in support of my view. Thus Hirsch ${ }^{5}$ records the case of a female domestic servant, 25 years old, who suffered from pain, vomiting, and hæmatemesis. The stomach was opened and as no ulcer could be found it was sewn up. The patient recovered completely. Armstrong ${ }^{6}$ records the case of a woman, aged 35 years, in whom there was no definite evidence of ulceration, although the bæmatemesis was severe. The author reports that "no deep excavated ulcer was found, but blood was seen onzing from three different places which looked like linear fissures in two cases and in the third like a stellate fissure. Around the fissures over an area of one centimetre there was an apparent loss of superficial epithelium." Here certainly there was no definite ulceration; the changes, if they existed, were no more than might be produced by blood in bursting through the epithelium. Mansell Moullin ${ }^{7}$ records the case of a woman, aged 34 years, whoše stomach was opened on account of severe hæmatemesis. He says : " One very small bleeding point was found on the posterio wall of the stomach near the pylorus. It could scarcely be called an ulcer." Both Armstrong's and Mansell Moullin's cases, like that of Hirsch, recovered completely. Gilford $^{8}$ operated on a woman, aged 30 years, who had suffered severely from bæmatemesis for 15 days. Although there had been hæmorrhage all this time and the stomach was most carefully examined both inside and out no trace of an ulcer could be seen. She died nine days after the operation and then an ulcer three centimetres in diameter was found. This, Gilford says, was in a position in which it could not have been missed during the operation, and therefore this case is an example of severe hæmorrhage lasting 15 days, and yet when the stomach was examined with the greatest care no ulceration could be found. It does not by any means prove that the disease which $I$ am describing naturally proceeds to ulceration; all it shows is that it may do so after the manipulation necessary to search for an ulcer. If subsequent experience should confirm this it clearly becomes important to diagnose, before operating, whether the blood proceeds from an actual ulcer.

As I have already mentioned, when the ulceration found

4 THe Lance'T, March 9th, 1901, p. 688

Berliner Klinische Wochenschrift, 1896, p. 847.

6 Brit. Med. Jour,, vol. ii., 1899, p. 1088

7 THE LANCET, Oct 20th, 1900, p. 1126

$\checkmark$ Guy's Hospital Reports, vol, liii. oy those who are earnestly seeking for it is trifling and superficial it is quite possible that it is the result of the bæmorrhage, for blood coming from the vessels into the cavity would naturally tear the epithelinm. Thus Gilford quotes from Weir and Foote two fatal cases; in both the ulcer was so minute that it was difficult to find it when the whole stomach was spread out in a good light. In one of the case its presence was positively shown only by transmitted light.

It has always seemed to me that as chlorosis is virtually confined to women at a period of high sexual activity the disease must be in some way connected with the function of reproduction, and $I$ would suggest that the disease which I am urging should be separated from gastric ulcer is perhaps so connected, and in support of this I may recall the fact that many have con. sidered that hæmatemesis may be vicarious menstruation and also the fact that these female sufferers may repeatedly come under observation for pain after food and hæmatemesis, but these symptoms wear themselves out before the menopause. Also, the association of this gastric ailment with chlorosis may, perhaps, be the reason for the frequency of the association of dyspepsia with chlorosis, for it may be that chlorotic dyspepsia is only a mild form of the same malady as causes severe pain after food and hæmatemesis, and in favour of this view I think it may be urged that severe dyspeptic symptoms are commoner with chlorosis than with other anæmias. My late house physician, Dr. A. E. Salter, acting on the views here expressed, has treated a large number of so-called gastric ulcers in young women with iron and good food and he finds that the patients do much better on this than on the usual treatment.

Lastly, I would call attention to the importance of separating gastric ulcer proper from this disorder, for the surgeon may find after he has opened the stomach that be can do nothing to control the hæmorrhage; some cases have died after operation, but the condition is of itself very rarely fatal. It is difficalt to see how anything but harm can follow operation when the mucous membrane is studded with bleeding points; and, indeed, Mayo Robson ${ }^{9}$ says . "Although the operative treatment of parenchymatous or capillary bæmorrhage by any surgical method would seem to be of doubtful value," and then he refers to five cases which died.

Harley-street, W.

\section{FOREIGN BODY IN THE BRONCHUS; TRACHEOTOMY ; RECOVERY.}

BY F. B. JUDGE-BALDWIN, M.R.C.S. GNG., SURGEON TO ROTHERHAM HOSPITAL.

IN following the bistory of foreign bodies in the bronchi the interest centres in the treatment, and that universally recommended is tracheotomy. This operation is called for firstly to lessen the danger from glottic spasm in the event of the foreign body moving and being coughed up; and, secondly, to afford a supplementary outlet for the foreign body itself. The further treatment consists in waiting for the development in the lung and dealing by direct operation with the possible-and probable-abscess that may arise. The following case adds one to the number of successes.

On Oct. 9th, 1900, a boy, aged five years, a very intelligent child, was coming home from school when be picked up a beech-nut, cracked it, put it into his mouth, and almost immediately began to choke. When met by a friend a few minutes afterwards he was still choking, his es es were suffused, and his face was reddish-blue in colour. A bout an hour or so afterwards he was hrought to my house becanse his roice "bad gone husky." The breathing was rapid, averaging from 25 to 30 respirations per minute, with some stridor, and with whispering speech, though the speerh was occasionally clear and the breathing free from stridor. I examined the larynx with the laryngoscope and found nearly complete bilateral paralysis of the adductors-i.e. the crico-arytænoïdei laterales and arytænoïdeus-but no foreign body could be seen. The trachea was clear for some four or five rings and was not unduly vascular. On stripping the patient and examining his chest I found considerable deficiency of respiration on the left side over an area of the 